\title{
Acute epiglottitis in a 79-year-old man
}

A case of acute epiglottitis in a 79-year-old man is presented describing the airway and anaesthetic management. Early reports of adult epiglottitis advocated observation or tracheostomy for airway management. Recent reports stress early endotracheal intubation. Unlike the paediatric age group adults may present with differing degrees of airway obstruction, epiglottic abscess, and with a more diverse set of medical problems. This can make ainway management more variable than in children. A discussion of airway management in adult eptglottitis is presented.

\section{Key words}

EPIGLOTTITIS: adult, airway management.

Adult epiglottitis has been reported more frequently in recent years. This may be due to an increased awareness of its occurrence or to an actual increased incidence.' Because of the relatively recent awareness of this disease and its infrequent occurrence, controversy exists over the management of the airway. Although the trend in airway management of adult epiglottitis has followed that of epiglottitis in the paediatric age group, there are differing factors which must be taken into consideration. The following case presentation and discussion illustrate this point.

\section{Case report}

A 79-year-old white man was transferred from an outside hospital with a two-day history of sore throat and dysphagia and a 12-hour history of inspiratory stridor. Lateral view radiographs of the neck showed an enlarged epiglottis and soft tissue

From the University of Michigan Medical Center, Department of Anesthesiology, Ann Arbor, Michigan. Address correspondence to: Betty Jean Muller, M.D., Department of Anesthesiology, Room A6061, Box 043, University of Michigan Medical Center, 1405 E. Ann Street, Ann Arbor, Michigan 48109. swelling over the posterior pharynx at the level of the third cervical vertebra (Figure). Past medical history included myocardial infarctions six and 13 years prior to admission, a stroke three months prior to admission which left no residual neurologic deficit, and adult onset diabetes mellitus.

In the emergency room the patient was sitting upright, mildly stridorous, and appeared to be in moderate respiratory distress. His temperature was $101.8^{\circ} \mathrm{F}$ and his respiratory rate was 35 . Auscultation of the chest revealed coarse rhonchi throughout. Arterial blood gases were $\left(\mathrm{FiO}_{2} 0.21\right)$ : $\mathrm{PO}_{2} 9.47 \mathrm{kPa}, \mathrm{PCO}_{2} 5.2 \mathrm{kPa}$, and $\mathrm{pH} 7.43$. The WBC count was 22,500 with a differential of 72 per cent segs, nine per cent bands, five per cent lymphs, and 14 per cent monos. Serum glucose was $328 \mathrm{mg} \cdot \mathrm{dl}^{-1}$.

The patient was brought to the operating room for

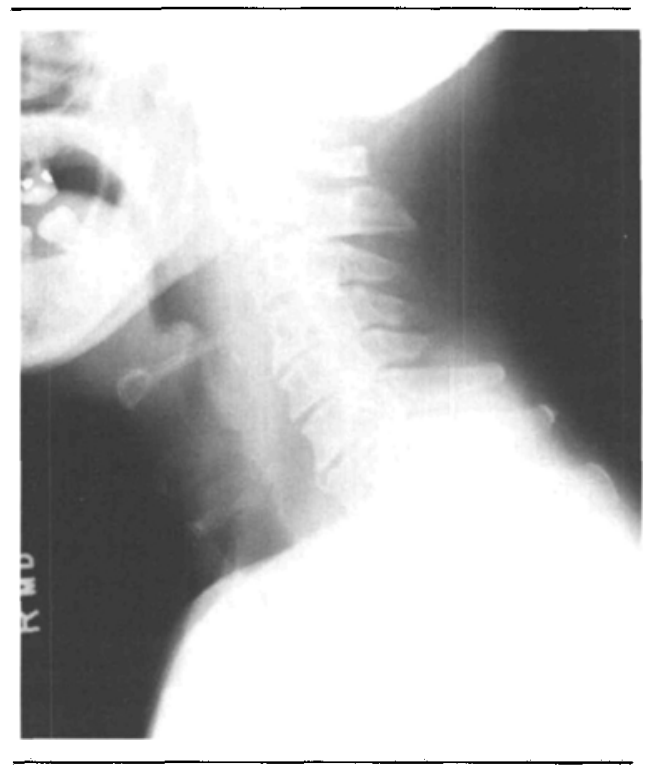

FIGURE Lateral view radiograph of the neck showing enlarged epiglottis and posterior pharyngeal oedema. 
tracheostomy and subsequent direct laryngoscopy. Tracheostomy was accomplished under local anaesthesia with the patient in a $60^{\circ}$ semi-recumbent position to facilitate respiration. While breathing 100 per cent oxygen through the tracheostomy tube, anaesthesia for direct laryngoscopy was induced with thiamylal and was maintained with isoflurane and a succinylcholine infusion.

Direct laryngoscopy revealed oederma of the supraglottic region, an edematous epiglottis, diffuse oedema of the left lateral pharyngeal wall and of the posterior pharynx. In addition there was left vocal fold paralysis and posterior commissure stenosis. The left arytenoid appeared to be fixed but the right vocal fold and arytenoid were observed to move normally.

Treatment with intravenous cefamandol was begun and the patient's temperature and WBC count returned to normal in four days. Throat and blood cultures did not grow pathogenic bacteria. The patient underwent repeat direct laryngoscopy seven days later which showed a normal epiglottis, some thickening of the mucosa of the left aryepiglottic fold and arytenoid, and persistent left vocal fold paralysis. Three days later the trachea was decannulated and the patient was discharged.

\section{Discussion}

Management of the airway obstruction in adult epiglottitis has evolved from observation with the administration of humidified air to tracheostomy and more recently to oral or nasotracheal intubation. ${ }^{2-4}$ Not all adults with epiglottitis present with severe respiratory distress and many have been successfully treated with humidified air or oxygen and antibiotics without an artificial airway. The incidence of successful management by this method ranges from 20 to 78 per cent. ${ }^{5,6}$ Patients presenting in severe respiratory distress or those who develop it subsequent to a period of observation have been treated by performing tracheostomy or more recently endotracheal intubation. Ward and Bishop have reported oral endotracheal intubation and Byrne has reported the use of nasotracheal intubation in adults with epiglottitis. ${ }^{4,5,7}$ Bishop advocates the use of endotracheal intubation before airway obstruction develops. ${ }^{5}$ All authors have stressed the need to perform laryngoscopy and intubation in the operating room with equipment and trained personnel ready to perform immediate tracheostomy.
Those who advocate endotracheal intubation argue that the disease is short-lived and an artificial airway generally would not be needed for more than five days. ${ }^{4}$ Additionally it spares the patient a surgical procedure and studies in the paediatric literature indicate a lower complication rate with endotracheal intubation vs. tracheostomy. ${ }^{5,8}$ But in the adult airway management by endotracheal intubation may not always be the preferred method. The present case illustrates this point. With advancing age there are frequently more concomitant illnesses which must be considered in the medical and anaesthetic management of the patient. With a history of two myocardial infarctions our patient may not have tolerated the myocardial depression associated with an inhalation induction of anaesthesia for laryngoscopy, endotracheal intubation, or tracheostomy. Vasodilatation caused by inhalation anaesthetics made hypotension during induction even more likely in view of his sitting position and the potential for intravascular volume depletion as a result of his dysphagia and febrile state. Hypotension in this patient could lead to myocardial and cerebral ischaemia. Induction of anaesthesia with an ultra-short acting barbiturate and succinylcholine was inappropriate as it could have led to a loss of the airway. For these reasons we felt a tracheostomy under local anaesthesia was the safest alternative.

An additional argument against the use of endotracheal intubation in the adult, especially nasotracheal intubation, relates to the occurrence of epiglottic abscess. This feature which is rare in children can enhance the airway obstruction but can also rupture with manipulation during intubation. The release of the abscess contents can cause laryngospasm and may spread the infection below the glottis into the lungs. ${ }^{9}$

In summary, early reports of adult epiglottitis advocated observation or tracheostomy for airway management. More recent reports have favoured early oral or nasotracheal intubation. Unlike the paediatric age group, adults with epiglottitis may present with differing degrees of airway obstruction, epiglottic abscess, and with a more diverse set of medical problems. This must be considered in airway management and may make it more variable than in children. 


\section{References}

1 Hawkins DB, Miller AH, Sachs GB, Benz RT. Acute epiglottitis in adults. Laryngoscope 1973; 83: 1211-20.

2 Matteson AR. Acute epiglottitis. Arch Otolaryngol 1962; 76: 465-8.

3 Gorfinkel HG, Brown R, Kabins SA. Acute infectious epiglottitis in adults. Ann Intern Med 1969; 70: 289-94.

4 Ward $C F$, Benumof $J L$, Shapiro HM. Management of adult acute epiglottitis by tracheal intubation. Chest 1977; 71: 93-5.

5 Bishop $M J$. Epiglottitis in the adult. Anesthesiology 1981; 55: 701-2.

6 Kander $P L$, Richards $S H$. Acute epiglottitis in adults. J Laryngol Otol 1977; 91: 295-302.

7 Byrne H, Hoel TM, Enoksen A. Acute epiglottitis in an adult treated with nasotracheal intubation. $\mathrm{Br}$ Med J 1977; 1: 1537-8.

8 Hannallah $R$, Rosales $J K$. Acute epiglottitis: current management and review. Can Anaesth Soc J 1978; 25: 84-91.

9 Guillozet $N$, Barclay AM. Obstructive epiglottitis in adults. J Fam Pract 1982; 15: 895-7.
Résumé

Un cas d'épiglottite aiguë chez un patient de 79 ans est présenté en même temps qu'une description de la conduite anesthésique et de maintien des voies aériennes. Les études antérieures sur l'épiglotite de l'adulte on proné l'observation ou la trachéostomie pour le maintien des voies aériennes. Les études récentes insistent sur l'intubation endotrachéale précoce. Contrairement au groupe pédiatrique, le groupe adulte peut présenter avec des degrés différents d'obstruction des voies aériennes, un abcès épiglottique et une variété de problèmes médicaux. Ceci peut rendre le maintien des voies aériennes plus variable que chez les enfants. Une discussion de la conduite à tenir pour le maintien des voies aériennes lors $d$ 'une épiglottite chez l'adulte est présentée. 